\title{
ASSESSMENT OF SAFER ROAD USER BEHAVIOUR
}

\author{
ABEER KHUDUR JAMEEL ${ }^{1,2}$ \& HARRY EVDORIDES ${ }^{2}$ \\ ${ }^{1}$ University of Mustansiriyah, Iraq \\ ${ }^{2}$ University of Birmingham, UK
}

\begin{abstract}
Road users are the primary and most important aspect of the transport system. Providing for user needs is the primary characteristic of a sustainable transport system. Road user behaviour is considered the main contributory factor to the majority of road accidents. Therefore, successful and effective strategic road safety plans focus on improving road user behaviour by considering seven road user risk factors: drinking-drivers, seatbelts, child restraints, speed management, wearing helmets, using a mobile phone while driving, and driving while under the influence of drugs. Law legislation and enforcement regarding these factors are adopted by the United Nations and the World Health Organisation as the most effective long-term approaches for improving road user behaviour, thereby improving the level of road safety. This research assesses the implementation of strategies for improving road user behaviour, and measures the extent to which these strategies have been successful in improving the overall level of road safety at a national level. An index is developed for each of the road user factors and aggregated to develop a road user assessment index. This index is used for monitoring progress in implementing the action of road safety law legislation and enforcement at the national level, and for comparing countries according to the behaviour of their road users. The results of the research show that not all countries consider all of the above noted risk factors in their road safety laws; furthermore, the ranking of countries according to the results of applying the developed index is different than the ranking calculated according to road deaths for roughly $60 \%$ of countries. It is recommended that other factors of road safety be addressed, and additional strategies for improving road user behaviour be adopted, according to how they have been implemented in countries that have achieved a significant decline in road fatalities.
\end{abstract}

Keywords: road user behaviour, road safety indicators, laws legislation and enforcement.

\section{INTRODUCTION}

Road safety is considered an important issue worldwide. Annually, more than million people are killed and 20 to 50 million people are injured on the road as a result of traffic accidents [1]. Factors leading to an increase in the rate of traffic and road accidents are addressed in documents published by global organisations such as the World Health Organisation and the United Nations [2], [3].

Traditional views on the road accidents problem is that road user behaviour serves as the main contributing factor in the majority of traffic accidents [2], [4]. On the other hand, the most recent practises for improving road safety level in Sweden and The Netherlands consider road safety as a system that comprises more than one element. A vision in these countries is based on the notion that elements of the transport system, roads and vehicles, should be designed to accommodate the limitations and vulnerability of the human body. This means that the mistakes of drivers can be corrected by the sustainable design of roads and vehicles [5]-[7]. However, exceeding the speed limit, driving under the influence of alcohol, and not using the protective systems provided in vehicles such as seatbelts, are types of mistakes that are related to the misbehaviour of road users. Therefore, improving road user behaviour is essential for avoiding mistakes that are considered as primary risk factors by the WHO in their assessment reports [1]. Road safety experts have demonstrated that effective road safety laws must considers these risk factors. Supporting this intervention with an 
effective enforcement system lead to significant improvements in road user behaviour, thereby improving the level of road safety [8].

The main aim of this research is to assess national road safety strategies in order to measure to what extent the risk factors in road user behaviour can be considered, and to assess the role of these factors on overall road safety levels. To achieve the aim of the paper, indicators will be defined and selected to reflect the main risk factors: speeding, consuming psychoactive substances (alcohol and drugs), using protective facilities (seatbelt, child restraints, and helmets), and using mobile phones while driving.

The following section will briefly present details regarding road user risk factors and their roles in increasing the rate and severity of road accidents. Following on, the primary steps of the methodology employed in this research will be explained. The results of applying the methodology will be presented and discussed. Finally, conclusions and recommendations will be presented.

\section{ROAD USER BEHAVIOUR}

The misbehaviour of drivers plays a significant role in the problem of increasing road risks. It is considered the main contributory factor in the majority of traffic and road accidents [2]. New visions for a road safety system are presented in "Vision Zero" from Sweden, and in "Sustainable Safety" from The Netherlands in the 90s. These campaigns consider the road user as the weakest factor in the transport system, due to the vulnerability and limitations of the human body. The practises in these campaigns are aimed at accommodating human weakness through the safer design of roads and vehicles. For example, the unintentional lane departing mistake can be avoided by providing lane separation devices on roads, and supported by a lane departing warning system in vehicles [5]-[7], [9]. These recent interventions assist in reducing the impact of unintentional mistakes made by drivers, which may be related to inexperience in terms of using roads. Other mistakes that can be considered intentional, such as not wearing a seatbelt and using mobile phones while driving, also cause road accidents and play a role in increasing the severe consequences of such accidents.

Best practises in countries that have achieved a significant decline in road deaths demonstrate that legislation and road safety laws, and supporting these with an effective enforcement system, is the best approach for improving road user behaviour [4], [10]-[12]. Such intervention is highly supported by the WHO [1], [2], [8], [13] which called for strengthening road safety laws in all countries by considering the most common intentional mistakes on roads. These mistakes are not only considered by the WHO as road risk factors, but are also considered in other research and studies as the primary indicators for road safety performance [14], [15]. These risk factors are classified in this paper into four categories: speeding, consuming psychoactive substances, using a protective system, and driving while distracted. These categories will be explained in the sub-sections below.

\subsection{Speeding}

Based on the safe system concept, it is essential to consider the impact energy between vehicles and people in the case of road accidents to reduce the severity of such accidents [10], [16]-[18]. Gitelman et al. [19], Woolley et al. [20], and UNRSF [11] state that setting speed limits can be considered as playing a role in preventing a third of fatal and serious crash injuries. ETSC [14] refers to studies demonstrating that a reduction of $1 \mathrm{~km} / \mathrm{h}$ results in a $3 \%$ reduction in the frequency of road accidents, and a 5\% reduction in the number of fatal accidents. Therefore, enhancing adherence to driving within the set speed limit is essential for gaining the benefits of setting a speed limit intervention [16], [21]. 
Speeding is a contributing factor in $30 \%$ of fatal road accidents [22]. Therefore, it is considered in the legislation of road safety laws. Providing an effective speed limit enforcement system is highly recommended by the WHO [8]. Different methods of police enforcement are recommended such as pursuing fine tuning [23]. For example, the Highway Code published by the transport department in the UK set the maximum fine of excessive speed limit by $£ 1000$ in case of 3 to 6 penalty points [24], [25]. Recent innovations assist in reducing the percentage of speeding drivers such as speed cameras, which has led to a reduction in the rate of speeding by about $70 \%$, and dropping the rate of fatalities by roughly $30 \%$ per annum in the UK, from 1990 to 2010 [8]. Mobile radar controls and electronic vehicle identification (EVI) are other examples of technologies used by police for speed enforcement [12]. Other types of innovation produced to help drivers avoid speeding mistakes include intelligent speed adaptation [26], speed exceedance alerts in vehicles, and speed humps on roads [16], [27].

\subsection{Psychoactive substances}

Drinking alcohol and driving is one of the most common contributory factors to serious road accidents [14], [28], [29]. It is suggested that roughly 14\% of road deaths in Europe [30], $41 \%$ in the US [31], and 32\% of fatal accidents worldwide occur as a result of this factor [2]. Researchers on this issue used blood alcohol content (BAC) to measure the effect of alcohol on drinking drivers' behaviour [18]. The risk of driving has been shown to double with each $0.02 \%$ increase in BAC [2]. In some countries that have achieved significant improvements in the level of road safety, drinking-driving laws have been passed based on a maximum BAC of $0.05 \mathrm{~g} / \mathrm{dl}$ for the general population, and $\leq 0.02 \mathrm{~g} / \mathrm{dl}$ for young drivers. This is reduced to $0.02 \mathrm{~g} / \mathrm{dl}$ for all drivers in some countries such as The Netherlands [8], [12], [30]. In the UK, drivers are prohibited to drive with a breath alcohol level higher than 35 microgrammes/100 millilitres of breath or a blood alcohol level of more than 80 milligrammes/100 millilitres of blood as shown in the Highway code published by the department of transport in 2015 and up[dated in 2018 [24], [25]. These laws have played a role in saving the lives of roughly $26 \%$ of road users [8], [32]. More than $9 \%$ of road users' lives are saved as a result of the enforcement of drinking driving laws (Elvik and Vaa, 2004, adapted by Hakkert et al. [32]). Strict penalties and fines are applied in some countries as an enforcement method when breath-testing indicates a BAC greater than the maximum limit [14], [30]-[33]. In the UK, for example, the maximum penalties set by the British parliaments is $£ 1000$ or in case of 6 to 11 recorded penalty points [24], [25]. In some countries, chemical test tubes have been used for detection purposes, prior to being replaced with electronic screeners [12].

Medical drugs are also included in the psychoactive substances that have recently been considered in the legislation of road safety laws. Two types of drugs are considered, legal drugs prescribed by doctors, and illegal drugs in abuse doses [32]. In the Netherlands, it is reported that half of the road risk related to psychoactive substances result from drinking alcohol, while the other half is divided equally among consuming drugs only and consuming drugs and alcohol [12]. Morphine and heroin are the most dangerous drug types in this case, and it is stated that the intake of these drugs leads to increasing the likelihood of an accident 32 times [32]. This is roughly 55 times less than the probability of an accident happening because of alcohol intoxication, and 47 times less than an accident occurring from drinking alcohol alongside drug intake. Bax et al. [33] demonstrate that cannabis showed the same effect as drinking alcohol within the allowed BAC. However, the method for testing drug content enforcement drug law remain challenging [30]. 


\subsection{Using protective systems}

Providing a protective system in vehicles is essential for reducing the level of road accident severity. This includes wearing a seatbelt, child restraints, and helmets for two-wheel vehicles.

\subsubsection{Using a seatbelt}

Seatbelt law legislation with firm police enforcement [8] can achieve significant improvements in the level of road safety. Increasing the rate of seatbelt use results in reducing the rate of road fatalities by roughly $40 \%$ to $65 \%$ [8], [19], [14]. Its effect on saving the lives of front-seat passengers is more significant than for rear-seat passengers, by roughly $25 \%$ [34]. Recent vehicle technologies such as seatbelt reminders and seatbelt ignition interlock [16] also helps to enhance the increase in seatbelt use by car users.

\subsubsection{Child restraints}

Developing child restraining seats in the front or back of a car [33], [35], and child restraint laws for both rear and front seats play a role in reducing fatal injuries among infants by roughly $70 \%$, and among children below the age of five by roughly 54\% [2], [8], [14], [19]. It also reduces serious injuries among children by roughly $90 \%$ [14]. Brubacher et al. [35] conclude that using child restraint law, together with public education and awareness campaigns, can produce better results.

\subsubsection{Two-wheel transport helmets}

Drivers and riders of two-wheel vehicles using helmets, as per national law regarding road safety, has a clear impact on reducing fatal and serious injuries by $20 \%$ to $45 \%$ for motorcyclists, and $60 \%$ to $80 \%$ for bicyclists [2], [15], [32]. It is also demonstrated that using motorcycle helmets can reduce the risk of head injury by almost 70\% [8], [14], [19], [35], while bicycle helmets can reduce the risk of head and brain injuries by $63 \%$ to $88 \%$ [36].

\subsection{Using mobile phones while driving}

Concerns have been raised regarding the problem of distracted drivers as a result of using mobile phones while driving [1], [37], [38]. Calling and texting messages by mobile phone while driving results in higher speed variations and longer reaction times [39]. Rahman et al. [37] refer to studies that demonstrate that the response time of drivers to a sudden event and taking action may be longer than for undistracted drivers, by more than a half second, and that the former require a longer distance to recover speed. This leads to increases in the road fatality rate by $6.6 \%$ to $100 \%$. Rahman et al. [37] also refer to Brace et al. (2007), whose research demonstrate that hand-held phones affect physical performance in addition to cognitive performance. Therefore, recently, road safety laws in most countries have moved to prohibit the using of a hand-held phone while driving [30]. For example, The UK Highway code presents a maximum penalty of $£ 1000$ for the light vehicles drivers and $£ 2500$ for the high vehicle drivers in case of using hand-held mobile phone with 6 recorded penalty points [24], [25].

\section{METHODOLOGY}

The main aim of this paper, as noted in the introduction section, is to develop an assessment index for safer road user behaviour. The concept of the index is based on a long-term improvement plan, by regulating road safety laws. These laws consider the risk factors addressed by previous studies and the assessment by the WHO [1], [14]. 


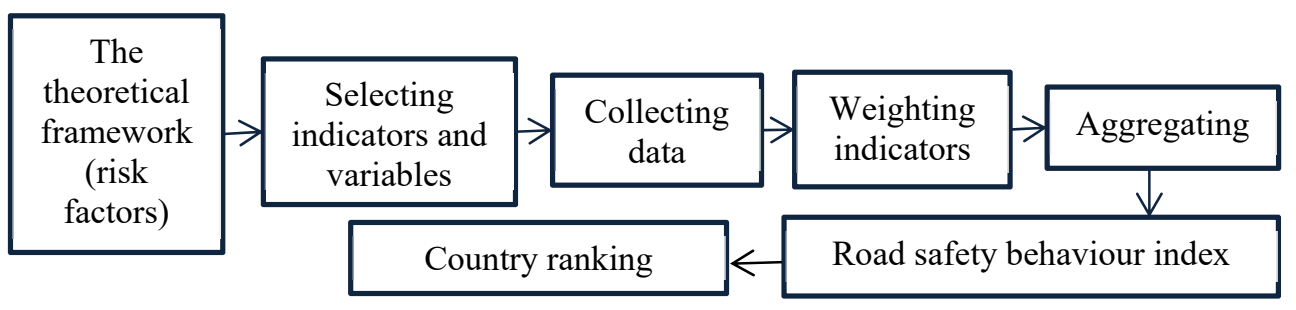

Figure 1: Methodology of the research.

To construct this index, six steps were followed as shown in Fig. 1. The first step focus on the phenomenon and the theoretical concept of the index to suggest the list of individual indicators combining the safer road user index. The final list of indicators will be decided in the second step based on the data availability which can use to measure the variables of the indicators. The required data are collected from reliable source which provides consistence data. The decided indicators are weighted then and aggregated to construct the required index which will be used to rank the countries. The results will be compared with actual crash rate to test they validity of the index. These steps will be explained in additional sections.

\section{THE THEORITICHAL FRAMEWORK}

In this step, the purpose of the index and the theory that the indicators are based on are defined. The purpose of identifying road user behaviour indicators and constructing the safer road user index is to use the index as an assessment tool. The assessment of road user performance is essential for monitoring the progress of interventions applied to improve road user behaviour, diagnosing the weakness of strategies, and for making comparisons between countries, thereby learning from a best practise strategy. The theory that the selected indicators in this research are based on regards the risk factors of road user behaviour that reflect the most common and dangerous intentional mistakes. These factors are speeding, consuming psychoactive substances, not using protective facilities, and being distracted due to using a mobile phone (see Table 1).

\section{SELECTING ROAD USER INDICATORS}

To select the relevant indicators, it is necessary to first define them according to type. Three types are defined in the Road Safety Strategy of New Zealand LTSA (2000) [14], which develops a road safety pyramid as valuable guide in the road safety management system. This pyramid is used in most of the road safety assessment studies in Europe, such as the SafetyNet, SUNflower and DaCoTA projects [14], [19], [28], [32], [40]-[42]. These indicators are final-outcome, performance, and policy output indicators. The final outcome indicators are represented either by the actual rate of road fatalities and injuries. The performance indicators are the intermediate outcome of road safety policy. For example, the percentage of drivers that wear a seatbelt is considered the performance indicators of seatbelt policy progress. The third type of indicators are the policy outputs that reflect the presence of road safety policy and strategies, such as road safety laws regarding the seatbelt strategy [43], [44]. The policy output indicator is the type of indicator developed in this research since 
it is related to implemented policy and strategies. The final outcome will be used in terms of road fatality rate per 100,000 population in order to compare with the results of this research.

\section{SELECTING VARIABLES AND COLLECTING DATA.}

Variables are used to measure the score of indicators. Since variables require data, the availability of reliable and consistent data represent essential criteria for selecting variables [45]. Other criteria are also important to consider in the selection of variables such as accuracy [46] and comprehensibility [47].

In this research, the availability of reliable and consistent data is the main criterion for selecting variables. The WHO assessment report [1] is therefore used as a reliable source of data. Since the developed index in this research will be used for comparing road user behaviour in a number of countries, it is important to use the available data in these countries, and to do so consistently. Table 1 shows the selected variables for the current research, their values having been collected from the country profile chapter according to the WHO [1]. The variables are presented in the form of yes/no questions. If the answer is "yes", the value of the indicator will be 1 . If it is "no", the value will be 0 . In the case of the enforcement indicator, the enforcement rate is the variable and the value is provided by the WHO [1]. In case of the BAC limit, the maximum $\mathrm{BAC}<0.05$ for general population and $<0.02$ for novice individuals are rated 1. If it is greater than this limit, the value of variables is reduced by 0.25 for each 0.01 over the maximum limit. This is based on the impact of the BAC limit on the life-saving rate, which is shown in section 2.2. Table 2 shows examples of the variable values for speeding and drunk-driving indicators.

\section{WEIGHTING INDICATORS}

To reflect the importance of the indicator impact on the road use behaviour index, assigning weights (wi) to indicators is essential. In this case unequal weights could be identified for each indicator depending on experts' opinion or statistical methods. In this paper, it is assumed that all indicators have an equal impact factor on road safety level, and all the selected indicators should be considered according to the same level. Therefore, equal weights are assigned to all the indicators selected in this research. $\mathrm{Wi}=1$ where wi is the weight of the indicator $i$.

This method is widely considered by a number of the most valid global indexes, such as the Human Development Index HDI and the Environmental Performance Index [33].

\section{AGGREGATING}

Combining all indicators in one composite indicator is achieved in this step. Linear arithmetic aggregation is the method used in this paper to aggregate the indicators into one index [45].

$$
(\mathrm{Sj})=\left(\sum_{1}^{n} I i * w i\right) / n
$$

where:

$\mathrm{Sj}=$ aggregated road user behaviour score for country $\mathrm{j}$

$\mathrm{Ii}=$ indicator i score $=1$

wi $=$ weight of Ii

$\mathrm{n}=$ number of indicators $=7$

The final score for the road user behaviour index are shown in Table 3. The final score is calculated by averaging the aggregated score of each indicator, then multiplying the result by 100 to convert it into a \% form. The final score is coded using five colours, each colour representing a range of scores. That is, the range between the maximum score and the minimum score is divided by five, as shown in eqn (1) 


$$
\text { range scale }=\frac{\text { maximum score-minmum score }}{5} \text {. }
$$

The highest score is represented by the green colour, which means the recommended policy for improving the behaviour of road users is being implemented well, while the black colour represents the countries that have not implemented the recommended policy. In the same way, countries are categorised by the true rate of road deaths per 100,000 population.

\section{DISCUSSION OF THE RESULTS}

The results of assessing the implemented policy for improving road user behaviour, and for avoiding the most common and dangerous mistakes reflected the road users' risk factors are presented in Table 3. The developed index is used to rank countries according to the score of the index. The results show that most of the high and middle income countries in Oceania, Europe, Latin America, and the Caribbean have implemented the strategies recommended by the WHO and the UN regarding the regulation of road safety laws, and support them with an effective enforcement system. This means that the behaviour of road users is at a safer level than in other countries. On the other hand, most countries in Asia and Africa have not implemented this policy in an effective manner.

Table 1: The indicators and variables for safer road user behaviour.

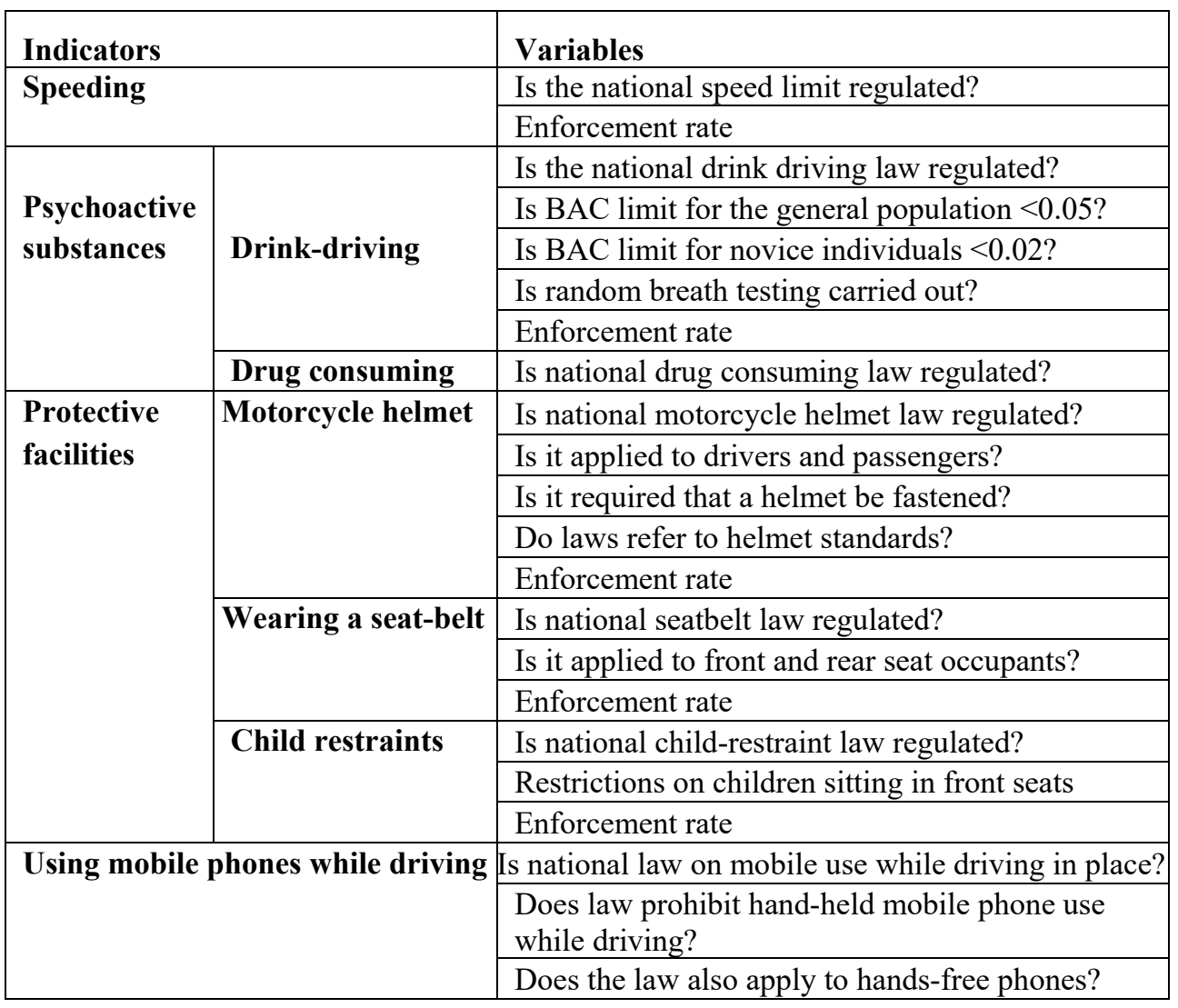


Table 2: Example of speeding and drinking-drivers indicators score calculated in this research.

\begin{tabular}{|c|c|c|c|c|c|c|c|c|c|}
\hline Country & 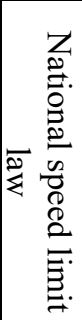 & $\begin{array}{l}\text { T1 } \\
\stackrel{0}{0} \\
0 \\
0 \\
0 \\
0 \\
0 \\
\stackrel{0}{0} \\
\overrightarrow{0} \\
\overrightarrow{0}\end{array}$ & 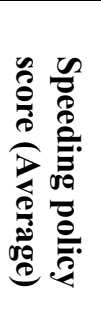 & 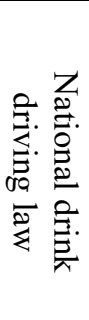 & 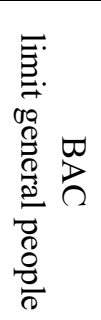 & 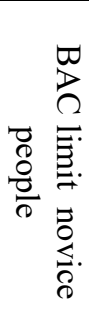 & 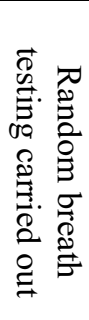 & 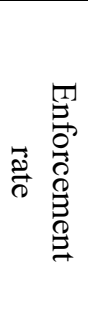 & 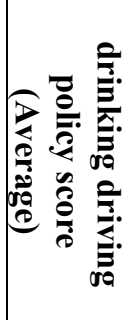 \\
\hline New Zealand & 1 & 0.8 & 0.9 & 1 & 1 & 1 & 1 & 0.9 & 0.98 \\
\hline Israel & 1 & 0.7 & 0.85 & 1 & 1 & 1 & 1 & 0.8 & 0.96 \\
\hline France & 1 & 0.9 & 0.95 & 1 & 1 & 0.25 & 1 & 0.8 & 0.81 \\
\hline Portugal & 1 & 0.7 & 0.85 & 1 & 1 & 1 & 1 & 0.7 & 0.94 \\
\hline
\end{tabular}

Table 3: The results of the aggregating and ranking countries by the developed index.

\begin{tabular}{|c|c|c|c|c|c|c|c|c|c|c|c|}
\hline Country & Region & 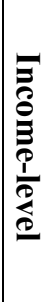 & 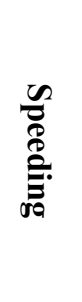 & 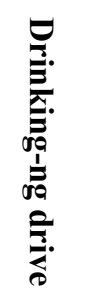 & 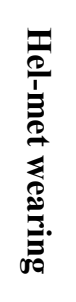 & 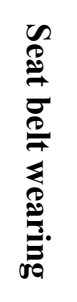 & 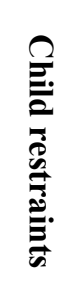 & 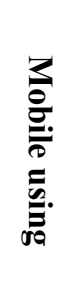 & 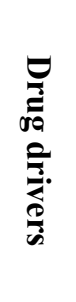 & 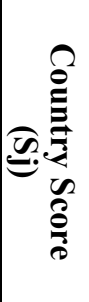 & 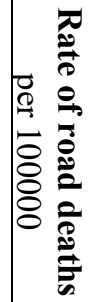 \\
\hline New? & $\mathrm{OCE}^{* *}$ & $\mathrm{H}$ & 0.9 & 8 & 98 & 7 & 0.97 & 0.67 & 92 & 0.38 & 6 \\
\hline Fran & & $\mathrm{H}$ & 0.95 & 31 & 0.98 & 0.97 & 0.93 & 0.67 & 90 & .21 & 5.1 \\
\hline Portugal & Eur & $\mathrm{H}$ & 0.85 & 0.94 & 0.98 & 0.93 & 0.93 & 0.67 & 0.90 & 6.20 & 7.8 \\
\hline Australia & OCE & $\mathrm{H}$ & 0.9 & 0.96 & 0.96 & 0.90 & 0.87 & 0.67 & 0.89 & 6.15 & 5.4 \\
\hline $\mathrm{Cr}$ & & $\mathrm{H}$ & 0.8 & 96 & 0.94 & 0.90 & 0.83 & 0.67 & .88 & 6.03 & 9.2 \\
\hline Russian & $\mathrm{Eu}$ & $\mathrm{H}$ & 0.9 & 0.87 & 0.92 & 0.90 & 0.87 & 0.67 & 0.87 & 6.00 & 18.9 \\
\hline Spain & Europe & $\mathrm{H}$ & 0.85 & 0.91 & 0.78 & 0.97 & 0.93 & 0.67 & 0.87 & 5.98 & 3.7 \\
\hline Nor & & $\mathrm{H}$ & 0. & 94 & & 0.93 & 0.87 & 0. & 0.87 & 5.98 & 3.8 \\
\hline Cuba & LCA & $\mathrm{M}$ & 0.8 & 0.76 & 0.78 & 0.93 & 0.80 & 1.00 & 0.87 & 5.94 & 7.5 \\
\hline Neth & Eurc & $\mathrm{H}$ & 0.85 & 0.94 & 0.74 & 0.90 & 0.90 & 0. & 0.86 & 5.85 & 3.4 \\
\hline & & $\mathrm{M}$ & 0.9 & .56 & 0.98 & 0.93 & 0.93 & 0. & 5 & 5.83 & 7.7 \\
\hline Lebanon & Asia & $\mathrm{M}$ & 0.75 & 0.9 & 0.84 & 0.77 & 0.67 & 1.00 & 0.85 & 5.77 & 22.6 \\
\hline Italy & Euro & $\mathrm{H}$ & 0.9 & 0.94 & 0.96 & 0.87 & 0.53 & 0.6 & 0.84 & 5.70 & 6.1 \\
\hline Bots & & $\mathrm{M}$ & 0.85 & & 0.92 & 0.90 & 0.73 & 0.67 & 0.83 & 5.67 & 23.6 \\
\hline Greece & Europe & $\mathrm{H}$ & 0.8 & 0.77 & 0.92 & 0.87 & 0.80 & 0.67 & 0.83 & 5.66 & 9.1 \\
\hline Canada & $\mathrm{NA}$ & $\mathrm{H}$ & 0.8 & 0.79 & 1 & 0.93 & 0.60 & 0.67 & 0.83 & 5.62 & 6 \\
\hline Poland & Europe & $\mathrm{H}$ & 0.75 & 0.96 & 0.58 & 0.90 & 0.93 & 0.67 & 0.83 & 5.62 & 10.3 \\
\hline Brazil & LCA & $\mathrm{M}$ & 0.85 & 0.56 & 0.92 & 0.90 & 0.87 & 0.67 & 0.82 & 5.59 & 23.4 \\
\hline Iran & $\Delta$ & $\mathrm{M}$ & 0.85 & 0.96 & 0.7 & 0.90 & 0.33 & 1.00 & 0.82 & 5.56 & 32.1 \\
\hline Australia & Europe & $\mathrm{H}$ & 0.85 & 0.96 & 0.78 & 0.87 & 0.60 & 0.67 & 0.82 & 5.54 & 5.4 \\
\hline Paraguay & LCA & $\mathrm{M}$ & 0.7 & 0.46 & 0.92 & 0.97 & 0.67 & 1.00 & 0.82 & 5.53 & 20.7 \\
\hline
\end{tabular}


Table 3: Continued.

\begin{tabular}{|c|c|c|c|c|c|c|c|c|c|c|c|}
\hline Country & Region & 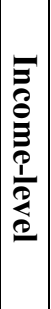 & 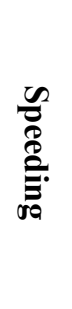 & 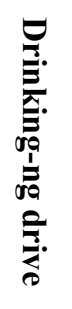 & $\stackrel{\frac{\pi}{0}}{\frac{2}{1}}$ & 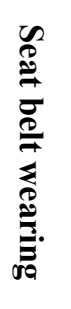 & 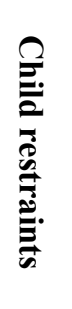 & 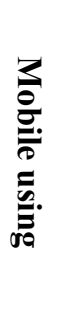 & 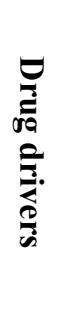 & 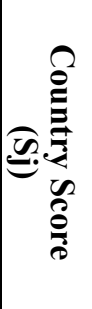 & 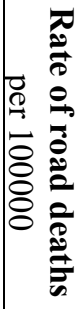 \\
\hline Singapore & Asia & $\mathrm{H}$ & 0.9 & 0.61 & 0.98 & 0.93 & 0.60 & 0.67 & 0.81 & 5.50 & 3.6 \\
\hline Algeria & Africa & $\mathrm{M}$ & 0.9 & 0.94 & 0.5 & 1.00 & 0.33 & 1.00 & 0.81 & 5.48 & 23.8 \\
\hline Cyprus & Asia & \begin{tabular}{|l|}
$\mathrm{H}$ \\
\end{tabular} & 0.85 & 0.79 & 0.54 & 0.90 & 0.90 & 0.67 & 0.81 & 5.45 & 5.2 \\
\hline Chile & LCA & $\mathrm{H}$ & 0.65 & 0.83 & 0.96 & 0.77 & 0.77 & 0.67 & 0.81 & 5.45 & 12.4 \\
\hline Turkey & Asia & $\mathrm{M}$ & 0.7 & 0.71 & 0.66 & 0.73 & 0.77 & 1.00 & 0.80 & 5.37 & 8.9 \\
\hline Albania & Europe & $\mathrm{M}$ & 0.8 & 0.75 & 0.68 & 0.90 & 0.77 & 0.67 & 0.79 & 5.36 & 15.1 \\
\hline Sweden & Europe & $\mathrm{H}$ & 0.8 & 0.96 & 0.96 & 0.93 & 0.57 & 0.33 & 0.79 & 5.35 & 2.8 \\
\hline Finland & Europe & $\mathrm{H}$ & 0.9 & 0.83 & 0.58 & 0.93 & 0.63 & 0.67 & 0.79 & 5.34 & 4.8 \\
\hline Angola & Africa & $\mathrm{M}$ & 0.75 & 0.65 & 0.68 & 0.93 & 0.80 & 0.67 & 0.78 & 5.26 & 26.9 \\
\hline Andorra & Europe & $\mathrm{H}$ & 0.8 & 0.81 & 0.98 & 0.60 & 0.57 & 0.67 & 0.77 & 5.20 & 7.6 \\
\hline Belgium & Europe & $\mathrm{M}$ & 0.85 & 0.75 & 0.78 & 0.87 & 0.50 & 0.67 & 0.77 & 5.19 & 6.7 \\
\hline Romania & Europe & $\mathrm{M}$ & 0.75 & 0.61 & 0.58 & 0.90 & 0.90 & 0.67 & 0.77 & 5.18 & 8.7 \\
\hline Bulgaria & Europe & $\mathrm{M}$ & 0.85 & 0.52 & 0.56 & 0.90 & 0.83 & 0.67 & 0.76 & 5.09 & 8.3 \\
\hline Colombia & LCA & $\mathrm{M}$ & 0.6 & 0.94 & 0.68 & 0.77 & 0.67 & 0.67 & 0.76 & 5.08 & 16.8 \\
\hline Eritrea & Africa & $\mathrm{L}$ & 0.75 & 0.77 & 0.56 & 0.87 & 0.70 & 0.67 & 0.76 & 5.07 & 24.1 \\
\hline Iceland & Europe & \begin{tabular}{|l|}
$\mathrm{H}$ \\
\end{tabular} & 0.8 & 0.75 & 0.58 & 0.87 & 0.63 & 0.67 & 0.76 & 5.05 & 4.6 \\
\hline China & Asia & $\mathrm{M}$ & 0.9 & 0.98 & 0.72 & 0.93 & 0.00 & 0.67 & 0.74 & 4.94 & 18.8 \\
\hline Ethiopia & Africa & $\mathrm{L}$ & 0.65 & 0.47 & 0.42 & 0.93 & 0.70 & 1.00 & 0.74 & 4.91 & 25.3 \\
\hline Ghana & Africa & $\mathrm{M}$ & 0.7 & 0.51 & 0.88 & 0.83 & 0.33 & 1.00 & 0.61 & 4.86 & 26.2 \\
\hline Malta & Europe & $\mathrm{H}$ & 0.8 & 0.55 & 0.56 & 0.93 & 0.60 & 0.67 & 0.73 & 4.84 & 5.1 \\
\hline Armenia & Asia & $\mathrm{M}$ & 0.85 & 0.59 & 0.74 & 0.87 & 0.33 & 0.67 & 0.72 & 4.77 & 18.3 \\
\hline Azerbaijan & Asia & $\mathrm{M}$ & 0.9 & 0.56 & 0.5 & 0.90 & 0.50 & 0.67 & 0.72 & 4.74 & 10 \\
\hline Nigeria & Africa & $\mathrm{M}$ & 0.8 & 0.49 & 0.72 & 0.60 & 0.40 & 1.00 & 0.72 & 4.73 & 20.5 \\
\hline India & Asia & $\mathrm{M}$ & 0.65 & 0.83 & 0.68 & 0.80 & 0.00 & 1.00 & 0.71 & 4.67 & 16.6 \\
\hline Saudi Arabia & Asia & \begin{tabular}{|l|}
$\mathrm{H}$ \\
\end{tabular} & 0.9 & 0.16 & 0.66 & 0.83 & 0.73 & 0.67 & 0.71 & 4.66 & 27.4 \\
\hline Denmark & Europe & $\mathrm{H}$ & 0.5 & 0.65 & 0.8 & 0.67 & 0.67 & 0.67 & 0.71 & 4.66 & 3.5 \\
\hline Bhutan & Asia & & 0.75 & 0.75 & 1 & 0.77 & 0.00 & 0.67 & 0.70 & 4.64 & 15.1 \\
\hline Georgia & Asia & $\mathrm{M}$ & 0.85 & 0.91 & 0.54 & 0.60 & 0.33 & 0.67 & 0.70 & 4.60 & 11.8 \\
\hline Ireland & Europe & $\mathrm{H}$ & 0.5 & 0.8 & 0.6 & 0.67 & 0.67 & 0.67 & 0.70 & 4.60 & 4.1 \\
\hline Bahrain & Asia & $\mathrm{M}$ & 0.85 & 0.54 & 0.58 & 0.57 & 0.67 & 0.67 & 0.70 & 4.57 & 8 \\
\hline UAE & Asia & \begin{tabular}{|l|}
$\mathrm{H}$ \\
\end{tabular} & 1 & 0.8 & 0.4 & 0.67 & 0.33 & 0.67 & 0.70 & 4.56 & 10.9 \\
\hline Korea & Asia & $\mathrm{H}$ & 0.9 & 0.61 & 0.72 & 0.90 & 0.00 & 0.67 & 0.69 & 4.48 & 12 \\
\hline Egypt & Africa & $\mathrm{M}$ & 0.75 & 0.92 & 0.5 & 0.60 & 0.33 & 0.67 & 0.68 & 4.45 & 12.8 \\
\hline UK & Europe & $\mathrm{H}$ & 0.5 & 0.45 & 0.8 & 0.67 & 0.67 & 0.67 & 0.68 & 4.43 & 2.9 \\
\hline Swaziland & Africa & $\mathrm{M}$ & 0.8 & 0.75 & 0.96 & 0.53 & 0.00 & 0.67 & 0.67 & 4.38 & 24.2 \\
\hline Sudan & Africa & $\mathrm{M}$ & 0.8 & 0.32 & 0.5 & 0.60 & 0.33 & 1.00 & 0.65 & 4.20 & 24.3 \\
\hline Thailand & Asia & $\mathrm{M}$ & 0.65 & 0.77 & 0.92 & 0.53 & 0.00 & 0.67 & 0.65 & 4.19 & 36.2 \\
\hline Kuwait & Asia & $\mathrm{H}$ & 0.75 & 0.8 & 0.54 & 0.43 & 0.33 & 0.67 & 0.65 & 4.17 & 18.7 \\
\hline Germany & Europe & $\mathrm{H}$ & 0.5 & 0.6 & 0.4 & 0.67 & 0.67 & 0.67 & 0.64 & 4.14 & 4.3 \\
\hline South Africa & Africa & $\mathrm{M}$ & 0.65 & 0.73 & 0.7 & 0.73 & 0.00 & 0.67 & 0.64 & 4.12 & 25.1 \\
\hline Zimbabwe & Africa & $\mathrm{L}$ & 0.85 & 0.53 & 0.78 & 0.60 & 0.00 & 0.67 & 0.63 & 4.06 & 1 \\
\hline Iraq & Asia & $\mathrm{M}$ & 0.65 & 0.64 & 0.24 & 0.50 & 0.33 & 1.00 & 0.62 & 3.99 & 20.2 \\
\hline Malawi & Africa & $\mathrm{L}$ & 0.75 & 0.51 & 0.96 & 0.47 & 0.00 & 0.67 & 0.62 & 3.98 & 35 \\
\hline Indonesic & sia & $\mathrm{M}$ & 0.75 & 0.9 & 0.76 & 0.60 & 0.00 & 0.33 & 0.62 & 3.96 & 15.3 \\
\hline
\end{tabular}

*Source: WHO site (2013), **Latin America and the Caribbean $=$ LAC, NA= North America, OCE $=$ Oceania. 
The results of comparing the ranking of countries using the developed index with the real rate of road fatalities shows that roughly $31.6 \%$ of countries have a worse safety level than the index reflects, e.g., Russia, Zambia, Iran, and Brazil. This means that strategies for improving road user behaviour have already been implemented, but they are not the main factor in road accidents in these countries. Other factors such as road and vehicle design factors must also be considered for the road safety strategies in these countries.

On the other hand, roughly $34 \%$ of countries have a better road safety level than indicated by the developed index, including Sweden, the Netherlands, the UK, and Canada. This means that the road safety improvement strategies in these countries consider other factors, which should be addressed and recommended to countries with a low road safety level to improve their road safety level.

\section{CONCLUSION}

Road user behaviour is an important factor of road safety. Most national road safety strategies consider the main risk factors related to the behaviour of road users in road safety laws. These factors are speed, consuming psychoactive substances (alcohol and illegal drugs), using protective facilities (seatbelts, child restraints, and helmets), and using mobile phones while driving.

Two aspects are demonstrated by the results of this research. The first is that not all risk factors are considered in the national road safety laws of most countries. The second is that road user behaviour can be improved by developing the safer design of roads and vehicles, as recommended by the WHO, as is evident in best practise countries such as Sweden and the Netherlands.

It is recommended that an index be developed to consider the indicators for safer road and vehicle design, and to aggregate such an index with the one developed in this research to assess the national road safety level and compare this with actual outcomes. If the results do not correlate, other factors will need to be considered to improve road user behaviour.

\section{REFERENCES}

[1] World Health Organization (WHO). Global Status Report on Road Safety. Online. http://apps.who.int/iris/bitstream/10665/44122/1/9789241563840_eng.pdf.

[2] Peden, M. et al., World Report on Road Traffic Injury Prevention Geneva, World Health Organization: Switzerland, 2004.

[3] UN: United Nations - Sustainable Development knowledge platform (Transforming our world: the 2030 Agenda for Sustainable Development), 2015.

[4] Larsson, P., Dekker, S.W.A. \& Tingvall, C., The need for a systems theory approach to road safety. Safety Science, 48(9), pp. 1167-1174, 2010. DOI: 10.1016/j.ssci.2009. 10.006 .

[5] Turner, B., Implementing the safe system approach to road safety: Some examples of infrastructure related approaches. Presented at 16th International Conference Road Safety on Four Continents, Beijing, China (RS4C 2013), 15-17 May, 2013.

[6] Belin, M.Å., Tillgren, P. \& Vedung, E., Vision zero: A road safety policy innovation. International Journal of Injury Control and Safety Promotion, 19(2), pp. 171-179, 2012. DOI: 10.1080/17457300.2011.635213.

[7] Turner, B. \& Jurewicz, C., Development and use of the austroads safe system assessment framework. Australasian Road Safety Conference, Canberra, Australian Capital Territory, Australia, Sep. 2016.

[8] World Health Organization. Strengthening Road Safety Legislation: A Practice and Resource Manual for Countries, World Health Organization, 2013. 
[9] Wegman, F., Dijkstra, A., Schermers, G. \& Van Vliet, P., Sustainable safety in The Netherlands: The vision, the implementation and the safety effects. SWOV, 2005.

[10] Larsson, P. \& Tingvall, C., The safe system approach: A road safety strategy based on human factors principles. International Conference on Engineering Psychology and Cognitive Ergonomics, Springer: Berlin and Heidelberg, 2013.

[11] UNRSF: United Nations Road Safety Collaboration, Global Plan for the Decade of Action for Road Safety 2011-2020, World Health Organization: Geneva, 2011.

[12] Wegman, F., Aarts, L. \& Bax, C., Advancing sustainable safety National road safety outlook for The Netherlands 2005-2020. Safety Science, 46, pp. 323-343, 2008.

[13] WHO: World Health Organization. Global Status Report on Road Safety: Supporting a Decade of Action. Online. www.who.int/violence_injury_prevention/road_safety_ status/2013. Accessed on: 27 Apr. 2015.

[14] ETSC: European Transport Safety Council, Transport Safety Performance Indicators, European Transport Safety Council: Brussels, 2001.

[15] Al-Haji, G., Road safety development index (RSDI). Theory, philosophy and practice. Linkoeping studies in science and technology, Dissertation No. 1100, Norrkoeping, Sweden, 2007.

[16] Organisation for Economic Co-operation and Development, Towards Zero: Ambitious Road Safety Targets and the Safe System Approach, Organisation for Economic Cooperation and Development, 2008.

[17] Corben, B.F., Logan, D.B., Fanciulli, L., Farley, R. \& Cameron, I., Strengthening road safety strategy development 'Towards Zero' 2009-2020 Western Australia's experience scientific research on road safety management SWOV workshop 16 and 17 November 2009. Safety Science, 48(9), pp. 1085-1097, 2010. DOI: 10.1016/j.ssci. 2009.10.005.

[18] Wegman, F., Aarts, L. \& Bax, C., Advancing sustainable safety National road safety outlook for The Netherlands 2005-2020. Safety Science, 46, pp. 323-343, 2008.

[19] Gitelman, V., Vis, M., Weijermars, W. \& Hakkert, S., Development of road safety performance indicators for the European countries. Advances in Social Sciences Research Journal, 1(4), pp. 138-158, 2014.

[20] Woolley, J., Stokes, C., Turner, B. \& Jurewicz, C., Towards Safe System Infrastructure: A Compendium of Current Knowledge Austroads Ltd. Austroads Publication No. AP-R560-18. Online. www.onlinepublications.austroads.com.au/ items/AP-R560-18.2018.

[21] Wegman, F.C.M. \& Goldenbeld, C., Speed management: Enforcement and new technologies. SWOV Institute for Road Safety, 2006(5), 2006.

[22] World Health Organization. Speed management: A road safety manual for decisionmakers and practitioners. 2008.

[23] May, M., Tranter, P.J. \& Warn, J.R., Towards a holistic framework for road safety in Australia. Journal of Transport Geography, 16(6), pp. 395-405, 2008. DOI: 10.1016/ j.jtrangeo.2008.04.004.

[24] Chorlton, K. \& Conner, M., Can enforced behaviour change attitudes: Exploring the influence of intelligent speed adaptation. Accident Analysis \& Prevention, 48, pp. 49$56,2012$.

[25] Gov.UK. Online. www.gov.uk/guidance/the-highway-code. Accessed on: Jun. 2018.

[26] Highway Code. Online. www.highwaycodeuk.co.uk. Accessed on: Jun. 2018.

[27] European Transport Safety Council. PRAISE: Preventing Road Accidents and Injuries for the Safety of Employees, How Can In-Vehicle Safety Equipment Improve Road Safety at work, Report 1. Brussels: European Transport Safety Council, 2009. 
[28] Wegman, F. et al., SUNflowerNext: Towards a composite road safety performance index. SWOV Institute for Road Safety Research, the Netherlands, Project Co-Funded by the European Commission within the Sixth Framework Programme (2002-2006), 2008.

[29] Hermans, E., A methodology for developing a composite road safety performance index for cross-country comparison. PhD thesis, Hasselt University, Belgium, 2009.

[30] Jackisch, J., Sethi, D., Mitis, F., Szymañski, T. \& Arra, I., European facts and the global status report on road safety. The Regional Office for Europe World Health Organization. Online. www.euro.who.int/en/publications. 2015.

[31] Ramstedt, M., Alcohol and fatal accidents in the United States: A time series analysis for 1950-2002. Accident Analysis \& Prevention, 40(4), pp. 1273-1281, 2008. DOI: 10.1016/j.aap.2008.01.008.

[32] Hakkert, A.S., Gitelman, V. \& Vis, M.A. (eds), Road safety performance indicators: Theory. Deliverable D3.6 of the EU FP6 project SafetyNet, 2007.

[33] Bax, C. et al., Developing a road safety index. Deliverable 4.9 of the EC FP7 project DaCoTA, 2012.

[34] Achterberg, F., Raising compliance with road safety law: 1st road safety PIN report. The European Transport Safety Council ETSC, 2007.

[35] Brubacher, J.R., Desapriya, E, Erdelyi, S. \& Chan, H., The impact of child safety restraint legislation on child injuries in police-reported motor vehicle collisions in British Columbia: An interrupted time series analysis. Paediatrics \& Child Health, 21(4):e27-e31, 2016. DOI: 10.1093/pch/21.4.e27.

[36] Shen, Y., Inter-national benchmarking of road safety performance and development using indicators and indexes: Data envelopment analysis based approaches. Doctoral dissertation, Hasselt University, 2012.

[37] Rahman, Z. et al., Evaluation of cell phone induced driver behavior at a type II dilemma zone. Cogent Engineering, 5(1), p. 1436927, 2018. DOI: 10.1080/ 23311916.2018 .1436927$.

[38] Gariazzo, C., Stafoggia, M., Bruzzone, S., Pelliccioni, A. \& Forastiere, F., Association between mobile phone traffic volume and road crash fatalities: A population-based case-crossover study. Accident Analysis \& Prevention, 115, pp. 25-33, 2018. DOI: 10.1016/j.aap.2018.03.008.

[39] Papadimitriou, E., Tselentis, D.I. \& Yannis, G., Analysis of driving behaviour characteristics based on smartphone data. Proceedings of 7th Transport Research Arena TRA 2018, Vienna, Austria, pp. 16-19, Apr. 2018.

[40] Gitelman, V., Doveh, E. \& Hakkert S., Designing a composite indicator for road safety. Safety Science, 38(9), pp. 1212-1224, 2010.

[41] Wegman, F. \& Oppe, S., Benchmarking road safety performances of countries. Safety Science, 48(9), pp. 1203-1211, 2010.

[42] Vis, M.A. \& Van Gent, A.L. (eds.), Road safety performance indicators: Country comparisons. Deliverable D3.7a of the EU FP6 Project SafetyNet, 2007.

[43] Papadimitriou, E. \& Yannis, G., Is road safety management linked to road safety performance? Accident Analysis \& Prevention, 59, pp. 593-603, 2013. DOI: 10.1016/ j.aap.2013.07.015.

[44] Hermans, E., Brijs, T. \& Wets, G., Developing a theoretical framework for road safety performance indicators and a methodology for creating a performance index. Steunpunt Mobiliteit \& Openbare Werken, 2008.

[45] European Commission-Joint Research Centre, Handbook on Constructing Composite Indicators: Methodology and User Guide, OECD Publishing, 2008. 
[46] Dobranskyte-Niskota, A., Perujo, A. \& Pregl, M., Indicators to assess sustainability of transport activities. European Commission, Joint Research Centre, 2007.

[47] Miller, H.J., Witlox, F. \& Tribby, C.P., Developing context-sensitive livability indicators for transportation planning: A measurement framework. Journal of Transport Geography, 26, pp. 51-64, 2013. DOI: 10.1016/j.jtrangeo.2012.08.007. 